\title{
On the Reform of Vocabulary Teaching in College English Reading Course
}

\author{
DU Yan \\ Zhoukou Normal University, Henan, China
}

\begin{abstract}
Vocabulary is the basis of English learning. The mastery of vocabulary directly affects the development of students' listening, speaking, reading, writing, translation, and other abilities. Therefore, vocabulary teaching plays an important role in English teaching. As a basic course for College English majors, one of the teaching objectives of reading course is to help students expand their vocabulary, enhance their sense of English language, and increase their cultural background knowledge of English speaking countries. In the process of extensive reading teaching, teachers should not be limited to the traditional vocabulary teaching mode, but should guide students to memorize words quickly and efficiently through flexible teaching methods, expand vocabulary, and at the same time, teachers should pay attention to the introduction of cultural knowledge in the process of vocabulary explanation, so as to help students understand the meaning more deeply and thoroughly.
\end{abstract}

Keywords: College English, reading course, vocabulary teaching reform

\section{Introduction}

Wilkins, a British applied linguist, once pointed out: "Without grammar very little can be conveyed, without vocabulary nothing can be conveyed.” (1972, p. 111). Vocabulary is the basis of English learning. Without rich vocabulary knowledge, students cannot catch the information in the article quickly and accurately, cannot understand the meaning correctly, and cannot read effectively in a short time. Therefore, the teaching of English vocabulary knowledge is also an important part of English reading teaching. English reading course is an important course in the basic stage of English major, also known as extensive reading course, which is a necessary supplement to intensive reading course. Students learn extensive reading course, which can improve reading comprehension ability and reading speed, enhance English language sense, expand vocabulary, and increase cultural background knowledge of English speaking countries (Wang \& Gao, 2008, p. 4). All of the above teaching objectives cannot be achieved without effective vocabulary teaching. Without certain vocabulary knowledge as a foreshadowing, it is difficult for students to carry out high-quality reading. Therefore, in the process of College English reading teaching, vocabulary teaching is an important part, which plays an important role in College English teaching, vocabulary teaching is a very important part.

The traditional vocabulary teaching mode is generally word centered, and students also spend a lot of time reciting and dictating. For example, "students are required to do some exercises, memorize words, and check their English vocabulary learning by means of class tests and stage tests” (Shao, 2019, p. 96). In the long run, students are prone to burnout when they memorize words, and cannot find the fun of learning words. It is

DU Yan, M.A., lecturer, College of Foreign Languages, Zhoukou Normal University, Henan, China. 
difficult for students to apply the knowledge of rote words to the real language environment. Therefore, taking the extensive reading course of College English as an example, on the basis of clarifying the existing problems of College English vocabulary teaching, this paper focuses on the analysis and research of College English vocabulary teaching reform and practice under the new situation, so that students can learn to understand vocabulary and its usage through association, induction, context, culture, and other aspects through reading course learning, so as to expand the vocabulary and improve the reading efficiency.

\section{The Main Problems in Vocabulary Teaching of College English Reading Course}

\section{Stylization of Vocabulary Teaching}

In the traditional vocabulary teaching, some teachers are used to teaching College English vocabulary with the textbook as the center, and the expansion of vocabulary is not enough, which limits the accumulation of students' vocabulary to a certain extent, and is not conducive to the expansion of students' vocabulary learning knowledge. In addition, some teachers have too single ways to consolidate and practice vocabulary knowledge, such as dictating words, doing word test questions, doing word matching questions, and so on. Even though students get high marks in the examination, they still have the problem of improper use of words in the practical application of language. Learning words in isolation from context is not conducive to students' mastering various usages of words, and a single way of assessing words is also difficult to see the specific situation of students' mastering words. Therefore, teachers should avoid the formalization of vocabulary explanation and the simplification of examination methods in the process of vocabulary teaching. In the process of teaching, teachers should give full play to all kinds of resources, stimulate students' enthusiasm of learning words through various teaching methods, and guide students to master the methods and strategies of memorizing words flexibly and efficiently.

Some teachers pay attention to the explanation of the knowledge of words and ignore the infiltration of the cultural information contained in the words in the teaching process, which makes the reading dull and uninteresting. In this teaching mode, students also become lifeless knowledge storage, listening passively instead of reading actively, which eventually brings that students' reading speed cannot be improved, reading quality cannot be guaranteed, thus losing interest and confidence in memorizing words, and even generating touch emotions for reading class.

\section{Word Memory Mechanization}

Because some students are used to memorizing the learned words by rote, in the eyes of many students, vocabulary learning is a very boring thing, but also a headache. In the process of extensive reading teaching, the author often heard students complain that the vocabulary is too large and the students have too many words to remember in a short time. This situation leads to individual students' fear of difficulty or boredom. They are unwilling to remember words and continue reading. As a result, a vicious circle is formed, resulting in a smaller and smaller vocabulary. When they take the exam, they feel helpless and lose interest and trust in English learning. In addition, because in the teaching process, the teacher focuses more on the content of the textbook, it is difficult for students to flexibly apply some words learned in the classroom to the actual life. Although they memorize the pronunciation or spelling of the words by rote, they cannot use the words properly in the local context, and they do not understand the usage of the words very thoroughly. This also leads to some college students' lack of interest and enthusiasm in English vocabulary learning. They feel that the words learned in 
textbooks are rarely used in daily life. As time goes on, they lose the enthusiasm and initiative in learning words, and the vocabulary is difficult to expand.

\section{College English Vocabulary Teaching Reform and Practical Strategies}

\section{Strengthen the Main Position of Students}

Students are the main body of learning and the main participants of learning activities, so teachers should strengthen students' main body status in vocabulary teaching. This requires teachers to consciously stimulate students' enthusiasm and initiative through flexible and diverse learning forms in the classroom. The teacher is no longer a person singing a monologue in the classroom, or taking full-scale teaching methods, but a guide, in terms of vocabulary memory methods and skills to guide students, inspire students to broaden their thinking space, and guide them to understand the meaning of words thoroughly. In class, teachers should give students more opportunities to show themselves and encourage students to express their understanding of words. In this way, students will no longer be the container of knowledge, passively accept the knowledge instilled by teachers, but can read skillfully under the inspiration and guidance of teachers, and experience the fun of obtaining information in the process of word recognition and memorization, so as to generate a strong desire for knowledge and exploration.

Of course, it is also a great challenge for teachers. First of all, teachers must fully prepare lessons, introduce a lot of relevant background knowledge to enrich the teaching content, expand the knowledge of students, and stimulate students' interest in reading. In this way, students will find the reading course lively and interesting, and will not feel bored and tired. Secondly, the teaching method should be flexible. The traditional reading teaching method, which is only satisfied with explaining vocabulary itself, is not conducive to activating students' thinking and improving students' reading ability. Therefore, the key to the reform of reading vocabulary teaching is to reform the traditional teaching mode and strengthen the students' main position. In this way, teachers can fully mobilize students' initiative in English learning and give full play to their potential.

\section{Improve Teaching Methods}

In the process of reading teaching, teachers should help students get rid of the bad habit of memorizing words, and guide students to form the memorization of words by means of different methods.

The first method is association. In the process of vocabulary teaching, teachers can guide students to memorize some scattered difficult and new words through association method according to the situation instead of mechanical memory and rote memorization of words. Associative memory can be divided into homophonic associative memory and Pinyin associative memory.

Homophonic associative memory is to associate the meaning of a word according to its pronunciation. This kind of memorization situation is more novel and interesting, and the students are willing to accept it, and the effect is better. For example, the word "merchant" can be remembered through homophonic association. The homophony of the word is very similar to “摸钱袋子” in Chinese Pinyin, that is, it is related to “钱”, and then it can be associated with the meaning of “做买卖, 经商” or “商品, 货物”. It should be pointed out that teachers should also remind students not to abuse association in reading. Taking the word "die maker" for example, many students associate it according to the meaning of "die". They think that the word must have a certain relationship with “death”, and their guesses are also various, such as “给死人化妆的人”, “做棺材的人”, 
and so on. In fact, “die maker” in the text means “压模工人, 制模工人”. Therefore, when students use associative memory to guess the meaning of a word, students should not take it for granted, but should find out the true meaning of the word according to the context or by looking up the dictionary.

The second method is to memorize the new words by context. In the process of extensive reading teaching, teachers should provide students with a certain language environment and create a certain situation, so that students can have a thorough understanding of their words and can apply them properly. Each word in the reading materials is not isolated, but connected with other words to produce meaning, so as to play the role of expression, and the meaning of each word can only be fully reflected in the language environment. If the teacher does not put the words into the sentences of the article and only teaches them in isolation, the students will feel bored and will not learn, remember, and use them correctly.

For example, the word "observe” has many meanings. "Do they observe Christmas Day in that country?" "He observed all the Negroes standing in breadlines and asked his parents about them...”.The first sentence is mainly about Christmas. It is easy to guess that "observe" means "celebrate”, which is equivalent to "celebrate”, and the second sentence involves Martin Luther King's sympathy for the poor, especially the black, when he was a child. In this situation, we can guess that the meaning of "observe" is equivalent to "to see and notice". Of course, the meaning of "observe" varies in different contexts and situations. When explaining the word, the teacher can first create a situation, or set a context, and then add a typical example sentence to explain, so that the word does not leave the sentence, word-sentence combination, sentence-sentence connection, so as to highlight the meaning and usage of the word, so as to help students deepen their impression, and use the learned word properly in real life, and improve students' communication ability.

Situational memory also includes memorizing words in real life situations, performance situations, or simulated communication situations. For example, when explaining the words, such as falter, embrace, stumble, tiptoe, etc. in the second volume of The Extensive Reading Course, the teacher can let the students get up and imitate the actions or sounds expressed by the words, which not only enlivens the classroom atmosphere, but also makes the students remember the meaning and usage of these words unconsciously.

In extensive reading, many students feel that there are too many new words to remember. In fact, the memory of words is not so difficult. As long as students choose the right memory method, they can get twice the result with half the effort. For instance, students can memorize the new words by inductive memory of parts of speech and of word formation. Inductive memory of parts of speech refers to the memory of words with the same root. For example, when students remember the word "relative", they can write down the meaning of “relation”, "relationship”, "relative”, "relativity”, and other words by the way. In this way, students can not only effectively expand the vocabulary, but also remember the meaning of words with different parts of speech of the same root. Take the word "workaholic" for example. In order to deepen students' memory of the word and expand their vocabulary, teachers can emphasize the suffix "-aholic" or "-oholic" of the word to indicate "crazy" or "people who are keen on something", then the teacher can sum up some common words with this affixation. In a word, inductive memory can not only help students to learn new words from the past, but also change the disordered state when they memorize words, so as to help students build confidence to break through the difficulty of new words.

In the process of teaching, the teacher should also pay attention to the introduction of cultural knowledge to help students to understand the cultural meaning of some words. Culture has a great influence on vocabulary. For example, many students can understand the literal meaning of the sentence "Fingers were made before 
forks", but they cannot understand the background knowledge of this sentence. This requires teachers to introduce corresponding cultural knowledge when explaining. Another example is the "Indian summer". Many students understand it as “印第安人的夏天”, which is also a misunderstanding caused by lack of cultural knowledge. First of all, "Indian” in "Indian summer” refers to the native Indians of America. "Indian summer” refers to “晚秋异常干燥暖和的一段时间, 往往出现在9月下旬、10月和11月”. It can be understood as “小 阳春” or “秋老虎” in Chinese. In addition, in different contexts, “Indian summer” has different meanings. It can also mean "the late period of prosperity" or "the happy and peaceful old age”. In addition, "Trojan horse”, "Pandora’s box", "Echo and Narcissus", and other expressions in the extensive reading course contain rich and interesting cultural background knowledge. In the process of extensive reading teaching, teachers can help students memorize words and enrich their cultural knowledge by introducing the knowledge of history and culture background, life customs, social etiquette, and other aspects of British and American countries, which can also increase the fun of students' learning.

In a word, in vocabulary teaching, teachers should not only grasp the shell but also understand its spirit, pay attention to the explanation of cultural knowledge, and avoid students' misinterpretation and misuse due to guessing the superficial meaning of the text, so as to greatly improve the reading quality.

\section{Innovation in Vocabulary Knowledge Assessment}

Teachers can test the effect of vocabulary teaching through flexible periodic tests. The traditional inspection methods are mainly written or written work. In order to stimulate students' interest, teachers can also examine students' vocabulary learning effect through various forms, such as word splicing, synonym replacement, word sentence making, word dubbing, etc., activate students' thinking and stimulate students' participation consciousness through teachers' creative and ingenious design.

\section{Conclusion}

Vocabulary is not only the basic element of language, but also the important foundation in the process of language learning. Vocabulary teaching is also an important part of College English reading teaching. Effective vocabulary teaching strategies help to improve students' English level. The teaching objectives of College English reading course include guiding students to expand their English vocabulary and accumulate cultural background knowledge through a large number of reading practice, so as to gradually improve their reading speed and understanding ability. In order to achieve this goal, teachers must help students to enhance their awareness and ability of vocabulary acquisition and strengthen their dominant position in reading teaching, To improve teaching methods, in the specific vocabulary teaching practice, teachers can help students remember the words better, understand the meaning more thoroughly, improve the ability of listening, speaking, reading, writing, translation, and other aspects, so as to comprehensively improve the ability of students to use the English language.

\section{References}

Shao, M (2019). On the reform and practice of College English vocabulary teaching in the new situation. Course Education Research, 51, 96-97.

Wang, S. R., \& Gao, H. (2008). Extensive reading course. Shanghai: Shanghai Foreign Language Education Press.

Wilkins, D. A. (1972). Linguistics in language teaching. Cambridge, MA: MIT Press. 